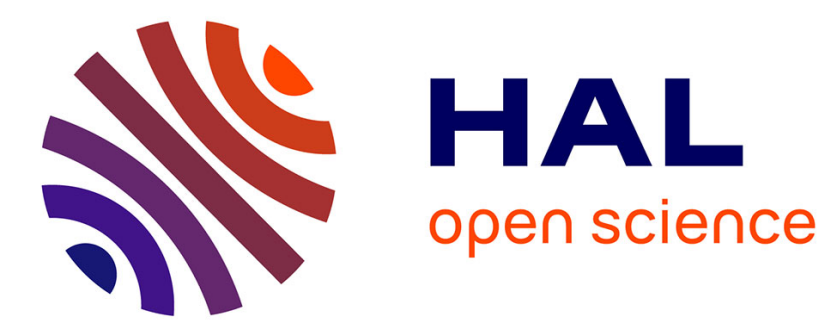

\title{
Perceived Social Norm and Behavior Quickly Adjusted to Legal Changes During the COVID-19 Pandemic
}

\author{
Fortuna Casoria, Fabio Galeotti, Marie Claire Villeval
}

\section{To cite this version:}

Fortuna Casoria, Fabio Galeotti, Marie Claire Villeval. Perceived Social Norm and Behavior Quickly Adjusted to Legal Changes During the COVID-19 Pandemic. 2020. halshs-02922335

\section{HAL Id: halshs-02922335 \\ https://shs.hal.science/halshs-02922335}

Preprint submitted on 26 Aug 2020

HAL is a multi-disciplinary open access archive for the deposit and dissemination of scientific research documents, whether they are published or not. The documents may come from teaching and research institutions in France or abroad, or from public or private research centers.
L'archive ouverte pluridisciplinaire HAL, est destinée au dépôt et à la diffusion de documents scientifiques de niveau recherche, publiés ou non, émanant des établissements d'enseignement et de recherche français ou étrangers, des laboratoires publics ou privés. 
UMR 5824

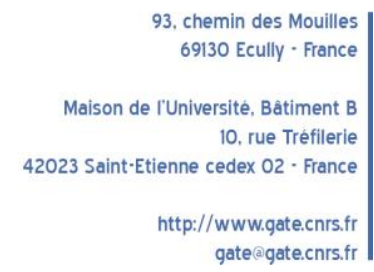

WP 2022 - August 2020

\title{
Perceived Social Norm and Behavior Quickly Adjusted to Legal Changes During the COVID-19 Pandemic
}

\author{
Fortuna Casoria, Fabio Galeotti, Marie Claire Villeval
}

\begin{abstract}
:
In response to the pandemic of COVID-19 and in lack of pharmaceutical solutions, many countries have introduced social and physical distancing regulations to contain the transmission of the virus. These measures are effective insofar as they are able to quickly change people's habits. This is achieved by changing the monetary incentives of rule violators but also by shifting people's perception regarding the appropriateness of socialization. We studied the effect of introducing, and then lifting, distancing regulations on the perceived norm regarding social encounters. We conducted an online incentivized experiment in France where we elicited the same participants' perceived norm and social distancing behavior every week for three months. We found that people shifted behavior and norm perception as soon as the government introduced or removed distancing measures. This effect was fast acting and long lasting. This is informative for future interventions, especially in light of a possible COVID-19 recurrence.
\end{abstract}

\section{Keywords:}

COVID-19, Social Distancing, Social Norms, Laws

JEL codes:

C9, D02, D91, H12, I12, I18

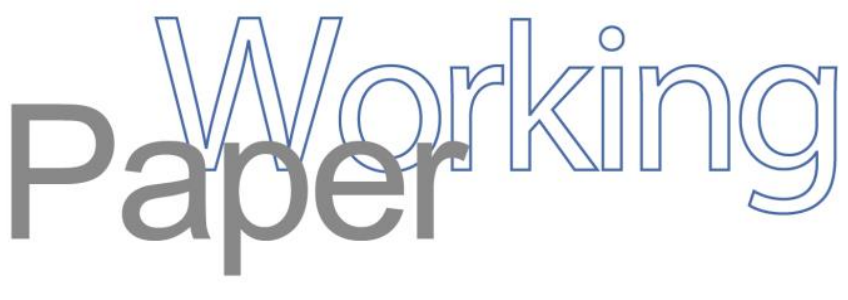


Perceived Social Norm and Behavior Quickly Adjusted to Legal Changes During the COVID-19 Pandemic

\author{
Fortuna Casoria $^{1}$, Fabio Galeotti ${ }^{1}$, Marie Claire Villeval ${ }^{1,2^{*}}$
}

${ }^{1}$ Univ Lyon, CNRS, GATE UMR 5824, 93 Chemin des Mouilles, F-69130, Ecully, France.

${ }^{2}$ IZA, Bonn, Germany.

*Corresponding author. E-mail: villeval@gate.cnrs.fr 


\section{Summary}

In response to the pandemic of COVID-19 and in lack of pharmaceutical solutions, many countries have introduced social and physical distancing regulations to contain the transmission of the virus. These measures are effective insofar as they are able to quickly change people's habits. This is achieved by changing the monetary incentives of rule violators but also by shifting people's perception regarding the appropriateness of socialization. We studied the effect of introducing, and then lifting, distancing regulations on the perceived norm regarding social encounters. We conducted an online incentivized experiment in France where we elicited the same participants' perceived norm and social distancing behavior every week for three months. We found that people shifted behavior and norm perception as soon as the government introduced or removed distancing measures. This effect was fast acting and long lasting. This is informative for future interventions, especially in light of a possible COVID-19 recurrence.

Keywords: COVID-19; Social Distancing; Social Norms; Laws 


\section{Main}

In 2020, the COVID-19 disease has rapidly spread worldwide through direct human contact and progressed into a global pandemic with enormous human health, economic and societal costs. As no vaccine or effective therapy is currently available to prevent or treat rapidly COVID-19, many governments have introduced new laws and regulations to limit social interactions and contain the spread of the disease. The success of these social and physical distancing measures (SPDM) crucially hinges on their ability to quickly change people's behavior and habits by shifting the perception of certain social norms, such as meeting friends, organizing social events or shaking hands (1-3). Indeed, the threat of being fined by the police in case of a violation probably exists (for example, in France 20.7 millions controls have been made between mid-March and the end of April, leading to 1.1 million fines, mainly for the lack of the circulation document; only $6 \%$ of the controls detected infractions to the law (4)). But it is probably not sufficient to deter such violations. While recent evidence based on available country-level data suggests that the combination of different large-scale anti-contagion policies (such as border closure, schools closure, and public events ban) decreases disease transmission (5-6), it is unknown how effective these interventions are at promoting social distancing behavior by changing the perceived social norm regarding face-to-face social interactions (7) (see also 8 for a very recent study we have just been aware of - their and our project developed independently and present different methodologies). In addition, it is unclear how the aforementioned social norm and its association with social distancing behavior would change again once certain restrictions are progressively lifted. Finally, a key question is how fast and persistent the change in the perceived norm and the associated behavior are after the introduction and the removal of SPDM. Indeed, social norms are usually considered as relatively sticky and they are not expected to change quickly (9). 
Understanding all this is important for the design of future interventions, especially when the risk of a second wave of infections still looms large (10).

In this study, we provide clear-cut causal evidence of the role played by the introduction and the subsequent removal of SPDM in shaping people's perception regarding the appropriateness of social gatherings (i.e., meeting friends for a social evening) and their effect on actual behavior. In contrast, broadcasted Presidential interventions did not lead to such an immediate change in perceived norms. We exploited data from an online, incentivized experiment conducted in France every week with the same participants over a span of three months: from March 18, 2020 (that is, as soon as the French government introduced SPDM) until June 24, 2020 (few weeks after the abrogation of these laws). The long duration of the experiment allowed us to assess the evolution of the norm and the associated behavior in response to changes in the law. 447 volunteers who registered originally were invited every week to complete three incentivized behavioral tasks and a survey. The behavioral tasks included a Social Value Orientation task (SVO) to measure participants' concerns for others (11), a trust game to measure participants' trust and trustworthiness (12) (reported in a companion paper), and a norm-elicitation task (13). In the norm-elicitation task, the participants indicated the social appropriateness of the behavior of a hypothetical person $\mathrm{X}$ who invited friends over for dinner last week. They earned money if they reported the same answer as the majority of the other participants.

To study changes in behavior, we asked participants to answer a number of questions on compliance with social distancing practices. In particular, participants indicated how often, in the previous week, they took part in social activities (e.g., visiting friends or family members, having face-to-face conversations with people not living with them). They answered on a 0-4 scale, where 0 meant "never" and 4 meant "every day". We elicited participants' subjective perception 
of the health risk with COVID-19 by asking them how concerned they were about the pandemic for their own health. We used a 1-10 scale, where 1 meant "not at all concerned" and 10 meant “extremely concerned". We also asked participants whether they had close relatives and friends diagnosed with COVID-19 and, in the last week of the experiment, whether they themselves had been diagnosed with the disease during the whole period of investigation. More details on our subject pool are contained in Supplementary Tables S1 and S2, while more information on our experimental protocol is reported in the Methods section.

We combined the experimental data with the information the French government provided during the three months of the experiment regarding the SPDM taken. On March 12 and 13, 2020 the French government announced that schools and universities would remain closed, that public gatherings (excluding public transport) with more than 100 people would not be allowed, and that all non-essential activities would not reopen, with immediate effect from either March 15 or 16 until further notice. On March 16, Emmanuel Macron went on television to announce the beginning of a nation-wide lockdown starting on March 17 for 15 days. Measures included the ban of all but the essential local travels, the interdiction of family or friend gatherings, and the closure of the French borders, among others. The French President also informed the public that all violations of these new regulations would result in penalty actions. The lockdown period was extended multiple times and was lifted only on May 11, 2020, though few restrictions remained in place (e.g., ban of gatherings with more than 10 people in public spaces, interdiction of travels exceeding $100 \mathrm{~km}$ from one's own residence) until late June. An advantage of the French setting for our analysis is that almost all SPDM were enacted roughly at the same time. This allowed us to estimate the effect of a sudden change in the law on the perception of the norm and on the associated behavior. 


\section{Results}

The experiment allowed us to collect measures of social appropriateness one week before the lockdown (week 0), during (weeks 1-8) and after (weeks 9-14) the lockdown. In particular, week 1 represents the legal threshold after which social gatherings were illegal, while week 8 represents the legal threshold after which social gatherings were legal again. Supplementary Table S3 in SI reports the mean appropriateness ratings, while Figure S1 in SI displays the full distribution of ratings for the three time-span periods. Mean ratings were constructed by converting subjects' responses into numerical scores using the same scale as in (13): "very socially inappropriate" $=-1$, "socially inappropriate" $=-2 / 3$, "somewhat socially inappropriate" $=-1 / 3$, "somewhat socially appropriate" $=1 / 3$, "socially appropriate" $=2 / 3$, "very socially appropriate" $=1$.

To investigate the impact of SPDM on the perceived social norm regarding social gatherings, we tested for the existence of a discontinuity in the norm at the two legal thresholds, week 1 (introduction of SPDM) and week 8 (abrogation of SPDM), using an OLS regression. We included a dummy variable for each week to capture the evolution of the perceived norm over time. We controlled for age, gender, education and occupation. Standard errors were clustered at the individual level. The results are reported in Table S4, Model (1), in SI. Figure 1 plots the average social appropriateness of inviting friends for dinner, over time. The two red dashed lines indicate the two legal thresholds. The figure shows a large effect of the introduction of the new regulation on the norm. As soon as SPDM were introduced, the average appropriateness dropped dramatically (from 0.63 in week 0 to -0.65 in week 1 ; Wald test, $p<0.001$ ), and it remained rather low and stable (but with a small increasing trend from about week 5) until week 8 (from -0.65 in week 1 to -0.53 in week 8 ; Wald test, $p<0.01$ ). Once the law was lifted and meetings 
with friends were allowed again, average appropriateness values increased (from -0.53 in week 8 to 0.05 in week 9 , Wald test, $p<0.001$ ), though less sharply than they dropped when the law was introduced. The perceived appropriateness of social gatherings then kept increasing gradually in the last 5 weeks until it reached a value of 0.51 in week 14 , which was close to prelockdown levels but still slightly below (from 0.63 in week 0 to 0.51 in week 14; Wald test, $p<$ 0.001). As a complement, Figure $S 2$ in $S I$ displays the variation in social appropriateness ratings between one week and the previous one, from a regression analysis controlling for participant's age, gender, education background and occupation. It reveals that the largest changes occur just after the introduction and after the lifting of the law.

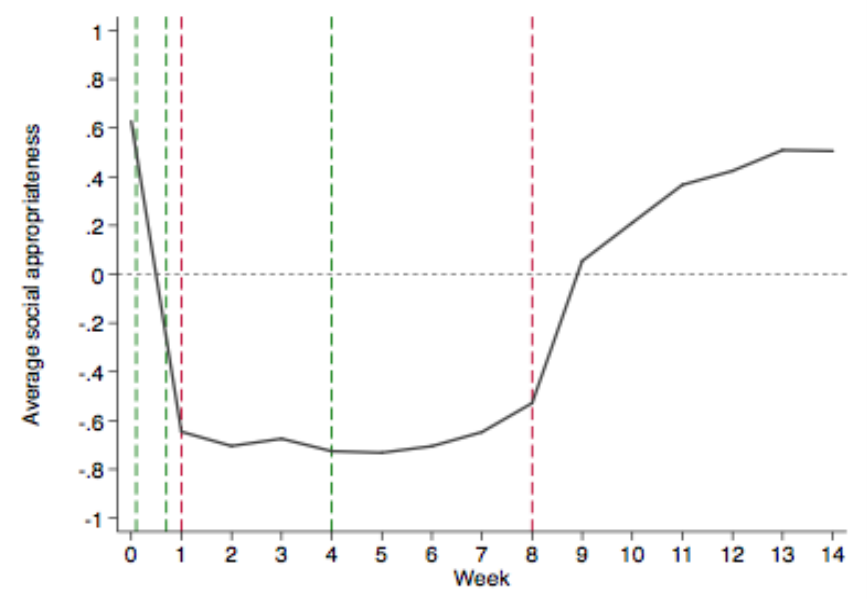

Figure 1. Average level of social appropriateness of inviting friends over for dinner for the period March 18-June 24, 2020. Each week, participants had to assess the social appropriateness of the following scenario: "Last week, "Person X" invited some friends to her house for dinner". The week numbers refer to the week in which the hypothetical scenario took place. In the first experimental session (March 18), the hypothetical scenario took place a week earlier (March 11), before the introduction of SPDM. We refer to it as week 0 . The red lines represent the two legal thresholds: introduction (week 1) and abrogation (week 8) of SPDM. The green lines represent three government nation-wide announcements: 
recommendations on social distancing (first line, March 12); introduction of the law (second line, March 16); lifting of the law (third line, April 13).

Next, we studied whether the change in the perceived social norm translated into change in behavior. Participants were invited to report whether they visited friends and/or family in person. We did not ask them whether they invited friends and family to visit them at home because we feared that it could be more perceived as an investigation of the violation of the law with possible consequences: being invited and inviting should be associated with a different feeling of responsibility. We performed a similar regression analysis as for the norm, except that we also included the perceived norm among the explanatory variables. The results are reported in Table S4, Model (2), in SI. Figure 2 plots the average frequency at which participants reported to have visited in person friends and/or family (see also Table S5 in SI). As a complement, Figures S3 and S4 in SI show the average frequency at which participants took part in other social activities. Figure 2 shows clearly that behavior followed a very similar pattern as the social norm: at the first legal threshold, there was a sharp drop in the average frequency at which participants met in person with friends and family (from 1.60 in week 0 to 0.16 in week 1 ; Wald test, $p<0.001$ ). During the lockdown, participants visited friends and family slightly more frequently over time (from 0.16 in week 1 to 0.51 in week 8; Wald test, $p<0.001$ ). After the law has been lifted, from week 9 onward, participants reported engaging in these activities more often (from 1.40 in week 9 to 1.82 in week 14 , Wald test, $p<0.001$ ). On average, in week 14 participants met in person more frequently than they did before the lockdown (from 1.60 in week 0 to 1.82 in week 14; Wald test, $p<0.01)$. Finally, visiting friends and family was positively associated with the perception of the norm: the more socially appropriate participants perceived social gatherings to be, the more they engaged in such behaviors (Wald test, $p<0.001$ ). 


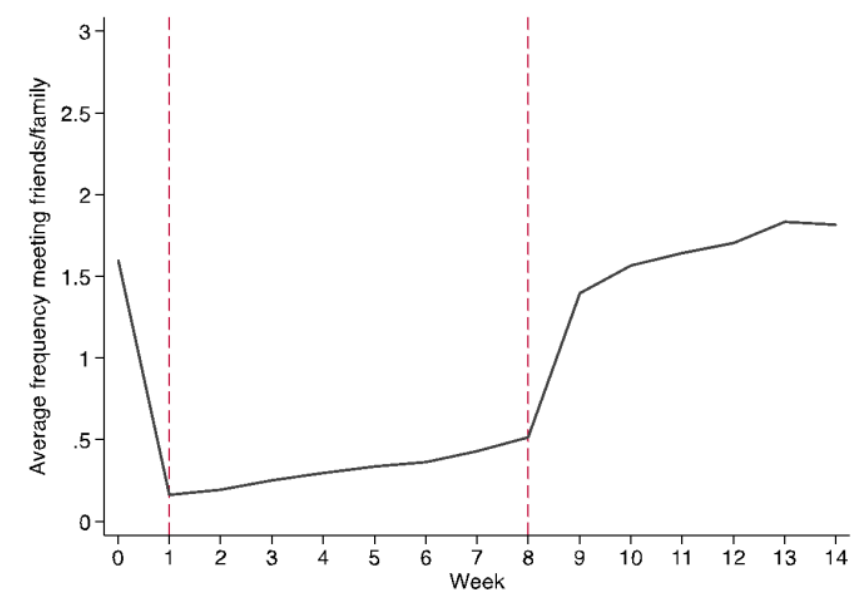

Figure 2. Average frequency of visits to friends and family over the period March 18-June 24.

Participants self-reported the frequency at which, last week, they visited friends and family members on a scale from 0 ("never") to 4 ("every day"). The week numbers refer to the week in which the participants visited friends and family members. In the first experimental session (March 18), the information corresponds to the visits to friends and family a week earlier (March 11), before the introduction of SPDM. We refer to it as week 0 . The red vertical lines represent the two legal thresholds: introduction (week 1) and abrogation (week 8) of the law.

\section{Discussion}

Our study suggests that SPDM strongly and very quickly influenced the perception of the social norm regarding meeting friends, and the associated behavior. As soon as social activities were banned, people considered them almost immediately as socially inappropriate and engaged less frequently in such activities. Interestingly, the perceived norm remained relatively stable while SPDM were in force, and the level of appropriateness only slightly increased when approaching week 9. These results are striking as the majority of our participants were young students (mean age: 23.79 y, S.D.: 6.87 y) with a large social network (mean network size: 313.56 friends, S.D.: 372.7) and an active social life (see Table $S 1$ in $S I$ ), and who might have perceived the epidemic 
as less threatening (indeed, cohort studies like (14), have concluded that risk increases exponentially with age). Our analysis also indicated that people's perception of the norm and the associated behavior almost returned to pre-lockdown levels few weeks after the removal of the bans, despite the recommendations of the French government to remain vigilant and behave responsibly. This suggests that the relaxation of social distancing measures may have reinstated previous habits and behaviors, perhaps too quickly, which could contribute to a resurgence of COVID-19 cases unless other measures are introduced (e.g., the obligation of wearing masks in public spaces). Our results are in line with theoretical studies that argued in favor of an expressive function of the law (15-21) and corroborates the few other empirical studies that assess the impact of laws on the perception of social norms $(8,22-27)$.

Already before the introduction of SPDM, the French government has warned against the dangers of social interactions and has promoted social isolation. Such recommendations might have affected the perceived social norm, so that the observed pattern is to be attributed to governmental announcements rather than to the introduction of the law. In Figure 1, the three green lines correspond to the three nation-wide announcements held by the French President. On March 12, 2020 (week 0), E. Macron urged people to respect measures such as hand-washing, limited travels and gatherings (28), and on March 16 he announced the introduction of the law on social distancing (29). As Figure 1 shows, inviting friends over was still considered socially appropriate in week 0 , while it was not in week 1 , once the law was introduced. Similarly, the announcement of April 13 (week 4), when E. Macron informed about the future lifting of the law (30), had very little effect on the social appropriateness rating: inviting friends for dinner was seen increasingly as more socially appropriate, but it was only after the law was formally lifted that the average social appropriateness returned to positive levels. The April 13's speech could 
have also been interpreted as a reminder of the law, since E. Macron announced that before being lifted on May 11, the lockdown would be prolonged for three more weeks. However, social appropriateness, if anything, started to increase after that speech, so it did not seem to work either as a reminder of the law. All these patterns suggest that even if they can somewhat signal the appropriateness or inappropriateness of some behaviors, government's recommendations alone are not sufficient to rapidly shift norms and coordinate beliefs, even in a time of acute sanitary crisis. This is an important implication for public policy.

It is also possible that the effect of the law on the norm was driven by how risky participants perceived the pandemic to be. Participants might have interpreted the introduction of a law that forbid social interactions as a signal of the danger that the disease posed and, therefore, they might have considered meeting other people as unsafe for themselves. On the contrary, the lifting of the law might have been seen as a signal that the virus was not spreading easily anymore and that meeting friends had become less dangerous. However, this analysis is not comforted by our data. Indeed, Figure 3 shows that, on average, participants tended to be less worried for their own health over time. The trend was decreasing even during the first weeks of the lockdown (left panel), notwithstanding the increasing number of confirmed cases and deaths (right panel), and the consequent greater exposure to the virus. 

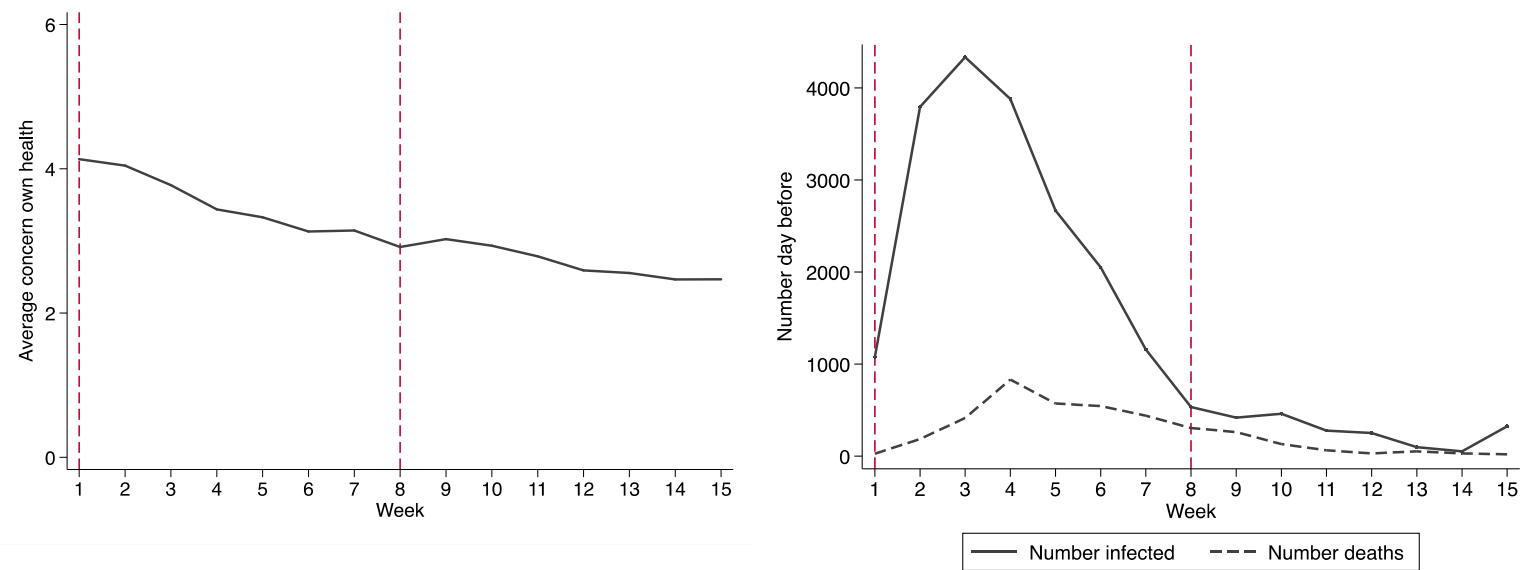

Figure 3. Left panel: Evolution over time of the average current concern for own health. Participants selfreported their current concern for their own health over the period March 18-June 24, 2020, on a scale from 1 ("not all concerned") to 10 (“extremely concerned"). Right panel: Number of COVID-19 confirmed cases (solid line) and deaths (dashed line) registered in France on the day before the experimental session.

Source: WHO database https://covid19.who.int/region/euro/country/fr. The red vertical lines represent the two legal thresholds: introduction (week 1) and abrogation (week 8) of the law.

While we could rule out that perceived riskiness of the disease for one's health explained the drop in perceived social appropriateness of social encounters, our design did not allow us to capture the effects of the perceived riskiness for others. Indeed, meeting friends was dangerous not only for oneself, but for others too. It is plausible that the influence of the law on the norm might be mediated by participants' care for their friends and family. However, we argue that this alone could not explain the jumps in social appropriateness exactly at the legal thresholds. Indeed, as already pointed out, the French government has recommended to reduce social interactions already before the introduction of the law. If caring for friends and family had an impact on the perceived norm, we would expect spending time with them being considered 
inappropriate independent of the law. Yet, most participants considered meeting friends appropriate for the majority as long as the law allowed it. In this respect, one might think that prosocial participants (i.e., participants who showed concern for the wellbeing of others) might have been more inclined to respect the law and more likely to consider violating the social distancing rules as socially inappropriate compared to individualistic participants (i.e., participants who showed concern only for their own wellbeing). The SVO task, which captured an individual's willingness to forgo some of their material payoff in order to increase the payoff of another person, allowed us to classify participants into prosocial and individualistic (see details in the comments of Table S6 in SI). Figure 4 plots the average social appropriateness of inviting friends for dinner (left panel) and the average frequency at which participants visited in person friends and family, separately for prosocial and individualistic types. Our results showed that there were no differences in the perception of the norm and the associated behavior for the two types of participants, and suggested that social preferences did not play a role in the observed patterns (this is confirmed by the regression analysis reported in Table S6 in SI).
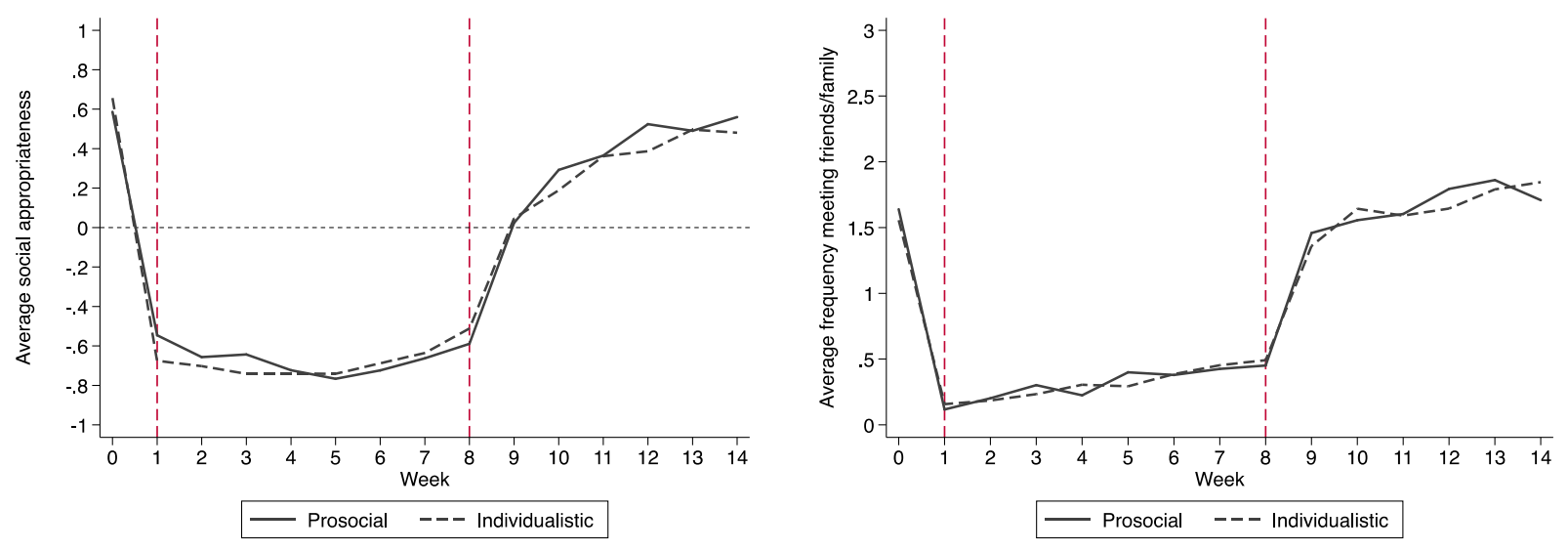

Figure 4. Left panel: Average level of social appropriateness of inviting friends over for dinner for the period March 18-June 24, 2020. Right panel: Average frequency of visits to friends and family over the period March 18-June 24, 2020. Data disaggregated by participant type: solid lines refer to participants 
classified as prosocial and dashed lines refer to participants classified as individualistic according to the SVO task. The red vertical lines represent the two legal thresholds: introduction (week 1) and abrogation (week 8) of the law.

Our study informs on the potential of SPDM to induce a change in behavior not only through deterrence, but also by altering the perception of what is the prevailing social norm regarding social activities. The observed sharp shift in the perception of the norm and in the associated behavior almost immediately after the introduction and the removal of social distancing measures highlights the importance of the law in shaping norms and behavior during a pandemic. In contrast, announcements by the government, even if widely listened to (for example the intervention of E. Macron on March 16 on the TV has been watched by 35.3 million citizens and that of April 13 by 36.7 millions), had not such an impact. The coordinating power of political discourse on people's beliefs seems much weaker than that of the law. These results are useful for policymakers who are considering whether and when to enact or remove social distancing measures. They indicate that it is the introduction of SPDM that causally affected people's perception of what constituted socially appropriate distancing behavior, and on their behavior itself. They suggest that the channel through which SPDM contribute to reduce the spread of the disease goes beyond the mere monetary disincentive from engaging in certain behaviors, and extends to the informal rules that regulate how people should behave in society. In addition, the effect of the introduction of SPDM was surprisingly fast and relatively long lasting: SPDM produced an immediate and substantial change in the perceived norm and behavior and this lasted several weeks after the introduction of these measures. Our results, however, also showed that the effect died quickly as soon as the measures were lifted. Social gatherings ceased to be perceived as socially inappropriate by the majority of people and, after a few weeks, the perceived norm and the associated behavior almost returned to pre-lockdown levels. 
At the time of writing, several countries are experiencing an unsettling re-emergence of COVID19 cases after lifting the lockdown. This is happening despite policymakers and health agencies frequently alert the public of the risks of new epidemic waves, and despite their recommendations to adopt protective and social distancing behaviors. Our study suggests that this resurgence may be driven by a post-lockdown social norm decay and that simple encouragement and information campaigns are not sufficient to prevent the resurgence of the epidemic, especially if these measures are unable to shift people's perception about what constitutes socially appropriate behavior. More legal-ground interventions may be needed to limit this decay and maintain more peri-lockdown normative standards.

\section{Materials and Methods}

Ethics approval was obtained from IRB-00003888 CEEI-INSERM, No. 20-665, in March 2020. We recruited 447 subjects within the GATE-LAB subject pool, Lyon, France. Subjects were 18 years old or older. Participants were recruited using the software Hroot (31). In the invitation email, we explained that the study would consist of 15 weekly short sessions (10 minutes on average, 15 minutes for the first session) and we recommended that the subjects participated in

all sessions. We informed the participants that they would receive a fixed payoff of $€ 2$ for each session they participate in (in total, they could earn up to $€ 30$ as a fixed payoff if they participated in all sessions), and that they would earn an additional variable payoff depending on their decisions and the decisions that all participants would make in the experiment.

Of the 447 participants that took part in the first session, 367 participated in the last session; 228 subjects participated in all 15 sessions. These numbers were on purpose beyond the minimum requested to detect a medium effect size (Cohen's $d=0.5)$ of the impact of the law, assuming a 
significance level of $5 \%$ and a power of $80 \%$, to anticipate the likely attrition. In the Results section, we report the analysis based on the full, unbalanced, sample. For information, we also report separate supplementary figures for the full and the balanced samples (see Supplementary Information). Visual inspection of these figures and statistical tests show that considering either the full or the balanced sample does not change qualitatively our results.

After accepting our invitation, at the beginning of the first session, participants were told that the experiment included a set of decisions, standard background questions (age, gender, education, occupation) and a number of questions on their personal life (such as number of friends, type of housing, use of social networks and contacts with family and friends). The session started only after the participants signed (electronically) the consent form. Participants were given the option of not answering all the health-related questions.

Each week, participants completed three incentivized behavioral tasks and a survey. In the SVO task, participants chose how to allocate money between themselves and another anonymous participant who changed each week. They made six decisions with different allocation options. In the trust game, participants decided how much money to send to another participant (trust), who then decided how much to send back (trustworthiness). Participants made both decisions without knowing in advance their role (first or second mover) and the decision of the counterpart. This means that, as second movers, they made a decision for each possible amount sent by the first mover (strategy method). In the norm-elicitation task, participants indicated the social appropriateness of the behavior of a hypothetical person $\mathrm{X}$ who invited friends over for dinner last week. They earned money if they reported the same answer as the majority of the other participants. That is we used a coordination game to elicit the perception of the norm, as social norms are collective perceptions of what one should or should not do. 
At the end of the study, we randomly drew either the SVO or the trust game for payment. For the SVO, we randomly selected two sessions and, for each session, one of the six decisions. A participant received the money that (s)he allocated to herself or himself for the first session, and the money that another participant allocated to him or her in the other session. For the normelicitation task, we paid participants for their decision in one randomly drawn session. If a participant did not participate in the session that was randomly drawn, his or her variable payoff for this session was null; this rule was made common knowledge to the participants from the very beginning and it was an incentive for participants to participate in all sessions. Earnings were paid either by bank transfer or in person at GATE-Lab from June 25 onward.

\section{References}

1. K. B. Habersaat, C. Betsch, M. Danchin, et al., Ten considerations for effectively managing the COVID-19 transition. Nature Human Behavior 4, 677-687 (2020).

2. J. J. Van Bavel, K. Baicker, P. S. Boggio, et al., Using social and behavioural science to support COVID-19 pandemic response. Nature Human Behavior 4, 460-471 (2020).

3. R. West, S. Michie, G. J. Rubin, R. Amlôt, Applying principles of behaviour change to reduce SARS-CoV-2 transmission. Nature Human Behavior 4, 451-459 (2020).

4. Declaration of the Minister of Internal Affairs, C. Castaner, May 11, 2020. https://www. lamontagne.fr/paris-75000/actualites/christophe-castaner-notre-doctrine-c-est-la-confiance _13786888/. Retrieved on July 20, 2020.

5. S. Flaxman, S. Mishra, A. Gandy, et al., Estimating the effects of non-pharmaceutical interventions on COVID-19 in Europe. Nature https://doi.org/10.1038/s41586-020-2405-7, (2020). 
6. S. Hsiang, D. Allen, S. Annan-Phan, et al., The effect of large-scale anti-contagion policies on the COVID-19 pandemic. Nature https://doi.org/10.1038/s41586-020-2404-8, (2020).

7. J. Haushofer, C. J. E. Metcalf, Which interventions work best in a pandemic? Science 368, 1063-1065 (2020).

8. R. Galbiati, E. Henry, N. Jacquemet, M. Lobeck, M., How Laws Affect the Perception of Norms: Empirical Evidence from the Lockdown. London, Centre for Economic Policy Research (2020).

9. C. Bicchieri, The grammar of society: The nature and dynamics of social norms. Cambridge University Press (2005).

10. López, L., Rodó, X. The end of social confinement and COVID-19 re-emergence risk. Nature Human Behaviour, 1-10 (2020).

11. O. Murphy, K. A. Ackermann, M. J. J. Handgraaf, Measuring social value orientation. Judgment and Decision Making 6, 771-781 (2011).

12. J. Berg, J. Dickhaut, K. McCabe, Trust, reciprocity and social history. Games and Economic Behavior 10, 122-142 (1995).

13. E. Krupka, R. A. Weber, Identifying social norms using coordination games: why does dictator game sharing vary? Journal of the European Economic Association 11, 495-524 (2013).

14. E. Williamson, et al., OpenSAFELY: factors associated with COVID-19-related hospital death in the linked electronic health records of 17 million adult NHS patients. (2020, mimeo available at https://www.atoute.org/n/IMG/pdf/fdrcoviduk.pdf).

15. C. Sunstein, On the expressive function of law. University of Pennsylvania Law Review 144, 2021-2053 (1996). 
16. R. Cooter, Expressive law and economics, Journal of Legal Studies 27, 585-608 (1998).

17. R. Cooter, Do good laws make good citizens? An economic analysis of internalized norms. Virginia Law Review 86, 1577-1601 (2000).

18. E. Posner, Symbols, signals, and social norms in politics and the law. The Journal of Legal Studies 27, 765-798 (1998).

19. E. Posner, Law and social norms (Cambridge, MA: Harvard University Press, 2000).

20. R. McAdams, An attitudinal theory of expressive law. Oregon Law Review 79, 339-390 (2000).

21. R. McAdams, A focal point theory of expressive law. Virginia Law Review 86, 1649-1729 (2000).

22. R. McAdams, E. Rasmusen, Norms and the Law, in Handbook of Law and Economics, M. Polinsky, S. Shavell, Eds. (Elsevier B.V., 2007), chap. 20, 1573-1618.

23. P. Funk, Is there an expressive function of law? An empirical analysis of voting laws with symbolic fines. American Law and Economics Review 9, 135-59 (2007).

24. M. Wittlin, Buckling under pressure: an empirical test of the expressive effects of law. Yale Journal on Regulation 28, 419-469 (2011).

25. M. E. Tankard, E. Levy Paluck, The effect of a supreme court decision regarding gay marriage on social norms and personal attitudes. Psychological Science 28, 1334-1344 (2017).

26. T. Lane, D. Nosenzo, Law and norms: empirical evidence (CeDEx Discussion Paper No. 2019-08, 2019).

27. A. Rees-Jones, K. Rozema, Price isn't everything: behavioral response around changes in sin taxes (2020, available at SSRN: https://ssrn.com/abstract=3205688). 
28. Broadcast of the President of the French Republic, E. Macron, March 3, 2020. https://www. elysee.fr/emmanuel-macron/2020/03/12/adresse-aux-francais. Retrieved on July 20, 2020.

29. Broadcast of the President of the French Republic, E. Macron, March 16, 2020. https://www. elysee.fr/emmanuel-macron/2020/03/16/adresse-aux-francais-covid19. Retrieved on July 20, 2020.

30. Broadcast of the President of the French Republic, E. Macron, April 13, 2020. https://www. elysee.fr/emmanuel-macron/2020/04/13/adresse-aux-francais-13-avril-2020. Retrieved on July 20, 2020.

31. O. Bock, I. Baetge, A. Nicklisch, Hroot: Hamburg registration and organization online tool. European Economic Review, 71, 117-120 (2014).

\section{Acknowledgments}

This research has been funded by Agence Nationale de la Recherche (ANR-20-COVI-0054, project DISTANCING). It has also benefited from the support of IDEXLYON (INDEPTH project, No. 183634) within the Programme Investissements d'Avenir (ANR-16-IDEX-0005). It has been performed in the framework of the LABEX CORTEX (ANR-11-LABX-0042) of Université de Lyon, within the program Investissements d'Avenir (ANR-11-IDEX-007) operated by Agence Nationale de la Recherche (ANR). We are grateful to Q. Thevenet for technical support.

\section{Contributions}

All authors contributed equally to the paper by conceiving the study, designing the experiment, analyzing the data and writing the paper. The authors declare no conflict of interest. 


\section{Online Supplementary Information}

Perceived Social Norm and Behavior Quickly Adjusted to Legal Changes During the COVID-19 Pandemic

Fortuna Casoria ${ }^{1}$, Fabio Galeotti ${ }^{1}$, Marie Claire Villeval ${ }^{1,2 *}$

${ }^{1}$ Univ Lyon, CNRS, GATE UMR 5824, 93 Chemin des Mouilles, F-69130, Ecully, France.

${ }^{2}$ IZA, Bonn, Germany.

*Corresponding author. E-mail: villeval@gate.cnrs.fr 


\section{Supplementary Figures}

A. Pre-lockdown (week 0)
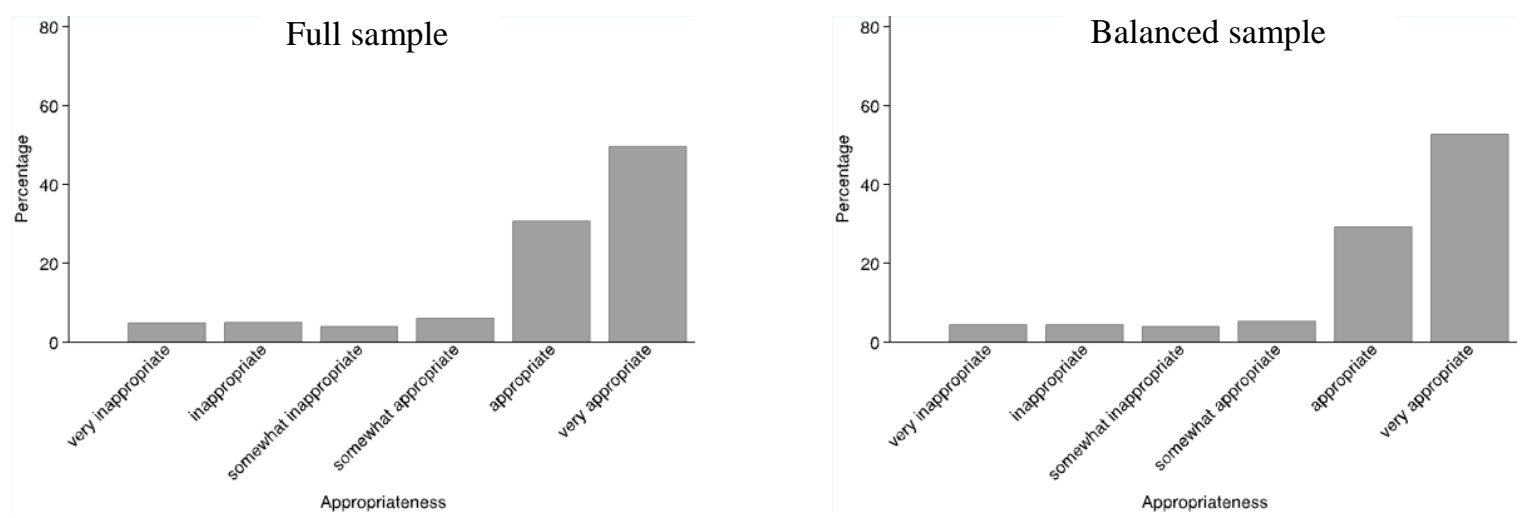

B. Lockdown (weeks 1-8)
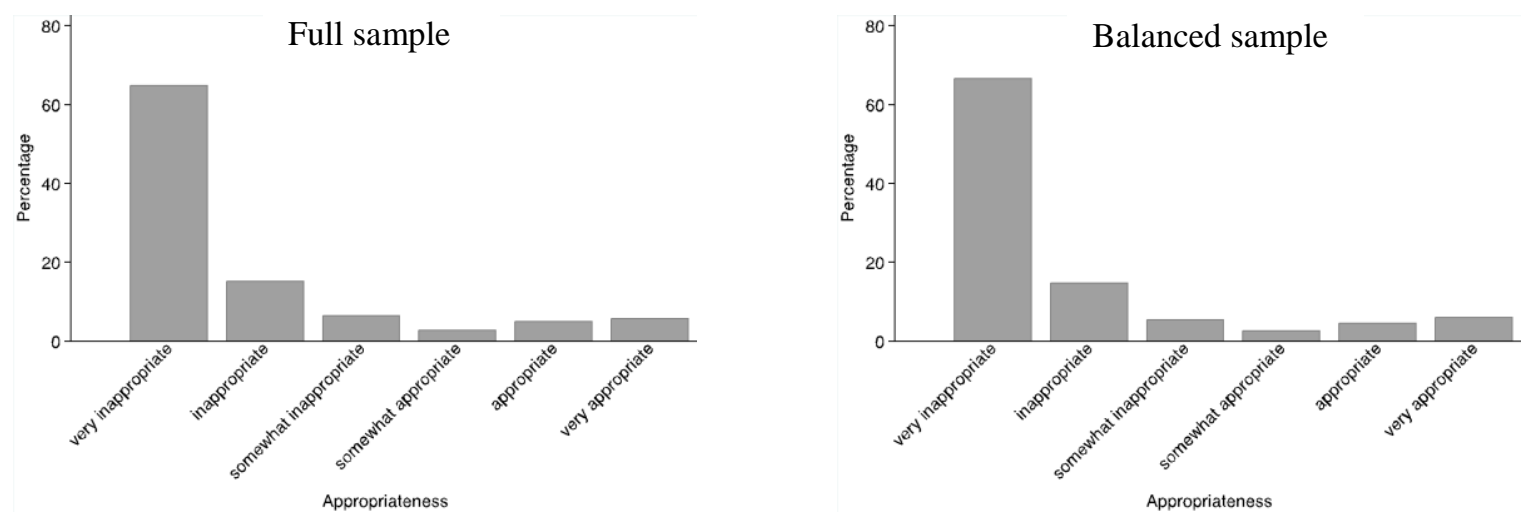

C. Post-lockdown (weeks 9-14)
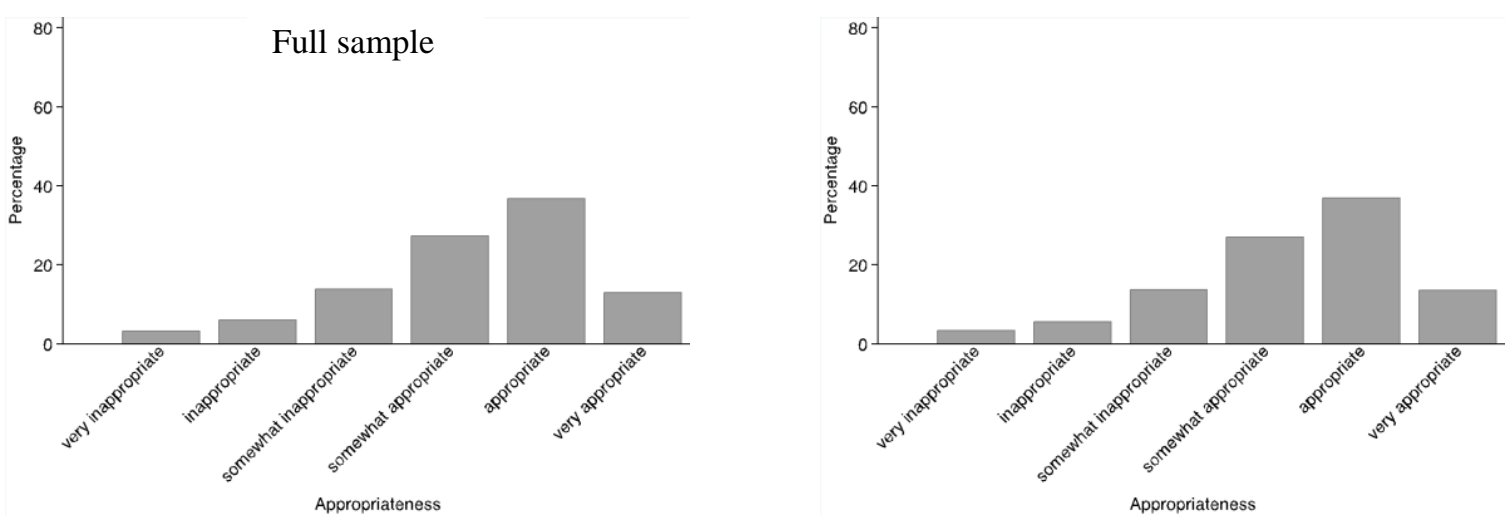
Figure S1: Distribution of social appropriateness ratings for the full sample (left) and the balanced sample (right).

Figure S1 reports the distribution of responses regarding the appropriateness of the behavior of a hypothetical person $\mathrm{X}$ who invited friends over for dinner last week. Possible responses were very inappropriate, inappropriate, somewhat inappropriate, somewhat appropriate, appropriate, and very appropriate. Panel A considers the pre-lockdown period, panel B the lockdown period and panel $\mathrm{C}$ the post-lockdown period. Figures on the left are for the full sample, regardless of whether individuals participated in the 15 sessions or not, while figures on the right only consider the sample of participants who did not miss any session. The distributions of responses are very similar between the full and the balanced samples. 

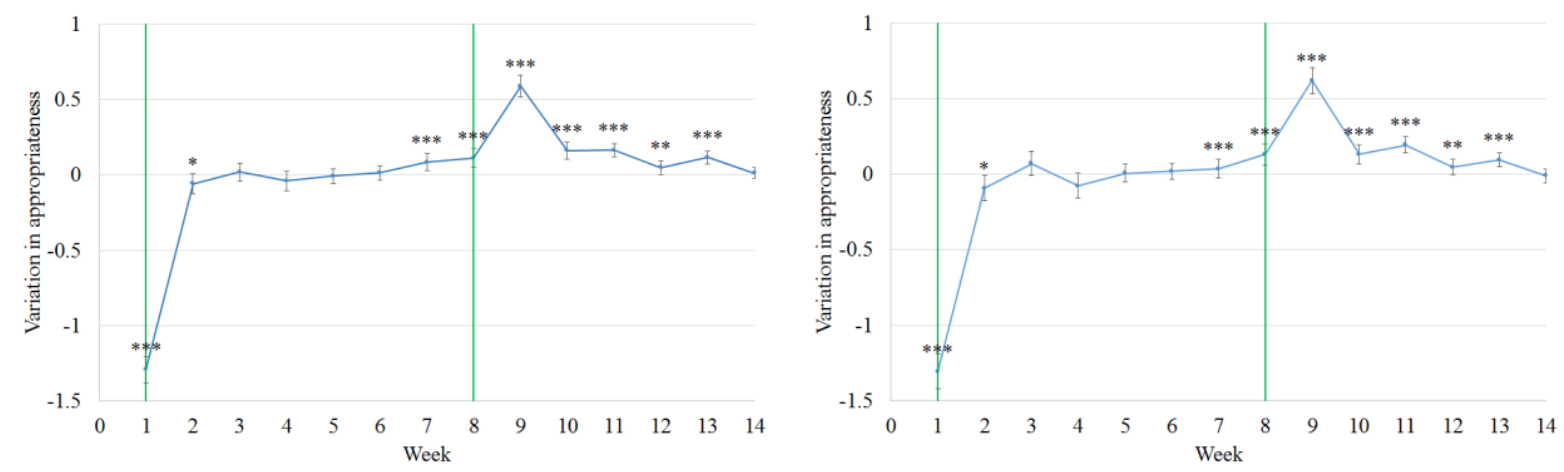

Figure S2: Evolution of the perceived norm (appropriateness rating) from a week to the next week over the period March 18-June 24 for the full sample (left figure) and the balanced sample (right figure).

The figure displays marginal effects from an OLS regression of the effect of time (dummy variables Week) on the variation in social appropriateness ratings between one week and the previous one, controlling for participant's age, gender, education background and occupation). In week 1 , the data point compares the evolution between week 0 and week 1 . *** $p<0.01$, ** $p<0.05$, $* p<0.1$.

The figure reveals that the largest changes occur just after the introduction and after the lifting of the law. 

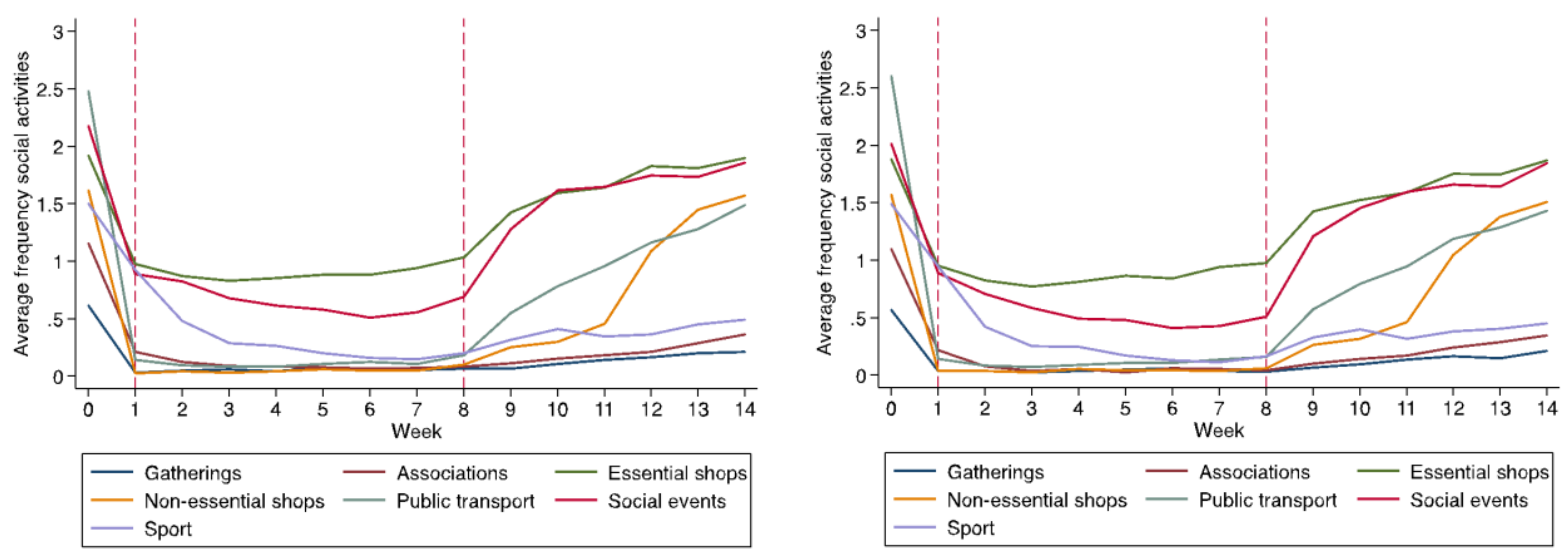

Figure S3: Average frequency of social activities in physical presence for the full sample (left figure) and the balanced sample (right figure).

The figures display the evolution of the mean frequency of various activities over time for the full sample (figure on the left) and the balanced sample (figure on the right). Participants reported on a scale from 0 ("never") to 4 ("every day") how frequently they engaged, the week before, in the following activities in physical presence: attending public gatherings (e.g., religious services, demonstrations, etc.); participating in the social activities of a club, company or associations; going to essential shops (e.g., supermarket, grocery store, pharmacy or medical center); going to nonessential shops (e.g., restaurant, bar, café, movie theatre, non-essential store); taking the public transport; attending or organizing a social event with family or friends (e.g., dinner, birthday party, wedding party, game night); playing sports or exercising with others (e.g., gym, swimming pool). The red vertical lines represent the two legal thresholds: introduction (week 1) and abrogation (week 8) of the law. 

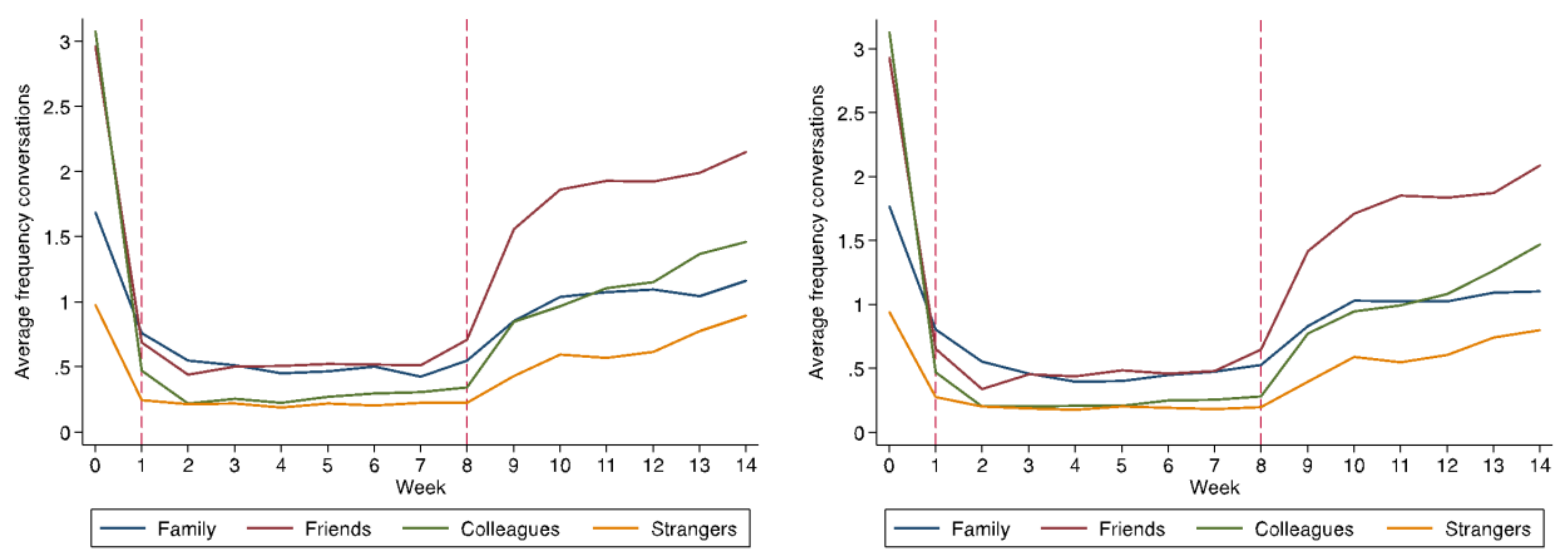

Figure S4: Average frequency of face to face conversations for the full sample (left figure) and the balanced sample (right figure).

The figures display the evolution of the average frequency of face-to-face conversations over time for the full sample (left figure) and the balanced sample (right figure). Participants reported on a scale from 0 ("never") to 4 ("every day") how frequently they had face-to-face conversations, the week before, with the following people living outside their home: family members, friends or neighbors, colleagues or fellow students, strangers. The red vertical lines represent the two legal thresholds: introduction (week 1) and abrogation (week 8) of the law. 


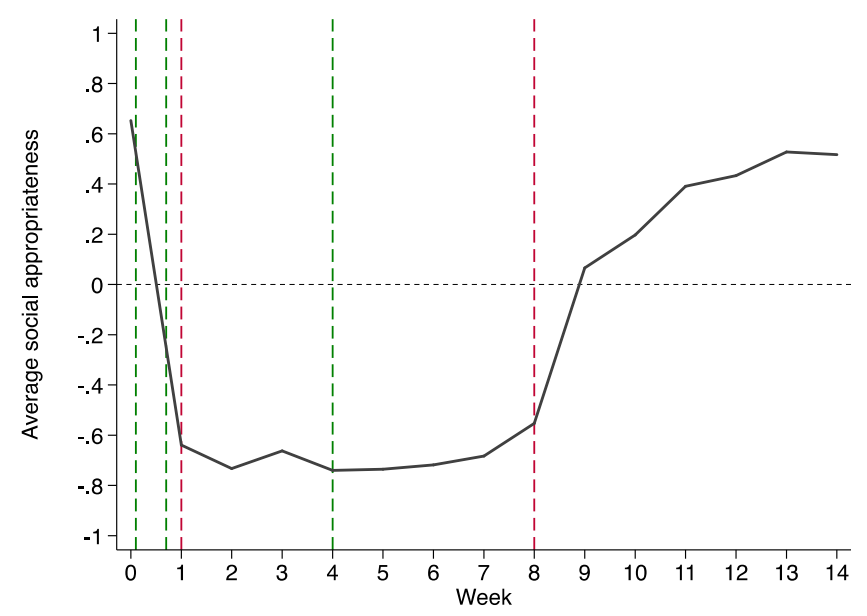

Figure S5: Average level of social appropriateness of inviting friends over for dinner for the period March 18-June 24, for the balanced sample.

The figure displays the evolution of the average perceived social appropriateness of inviting friends over for dinner over time for the balanced sample. It is equivalent to Fig. 1 for the whole sample. Each week, participants had to assess the social appropriateness of the following scenario: "Last week, "Person X" invited some friends to her house for dinner". Mean ratings were constructed by converting subjects' responses into numerical scores using the same scale as in Krupka and Weber (2013): "very socially inappropriate" $=-1$, "socially inappropriate" $=-2 / 3$, "somewhat socially inappropriate" $=-1 / 3$, "somewhat socially appropriate" $=1 / 3$, "socially appropriate" $=2 / 3$, "very socially appropriate" $=1$.

The week numbers refer to the week in which the hypothetical scenario takes place. In the first experimental session (March 18), the hypothetical scenario took place a week earlier, before the introduction of the law. We refer to it as week 0 . The red vertical lines represent the two legal thresholds: introduction (week 1) and abrogation (week 8) of the law. The green lines represent government nation-wide announcements: recommendations on social distancing (first line, March 12); introduction of the law (second line, March 16); lifting of the law (third line, April 13). 


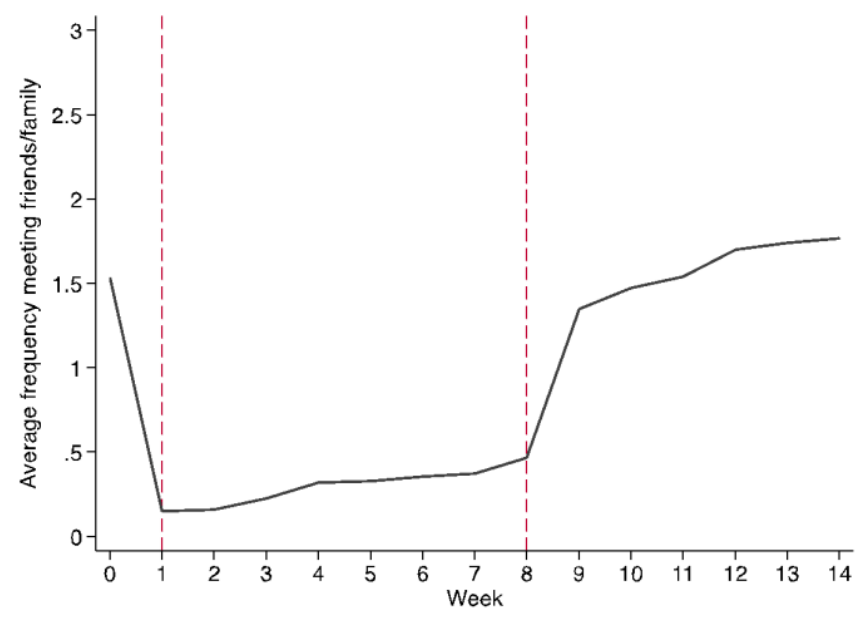

Figure S6: Average frequency of visits to friends and family over the period March 18-June 24, for the balanced sample.

The figure displays the evolution of the average frequency of visits to friends and family over time for the balanced sample. It is equivalent to Fig.2 for the whole sample. Participants self-reported the frequency at which, the week preceding the current one, they visited friends and family members by choosing an answer on a 0-4 scale, where 0 means "never" and 4 means "every day". The red vertical lines represent the two legal thresholds: introduction (week 1) and abrogation (week 8) of the law. 


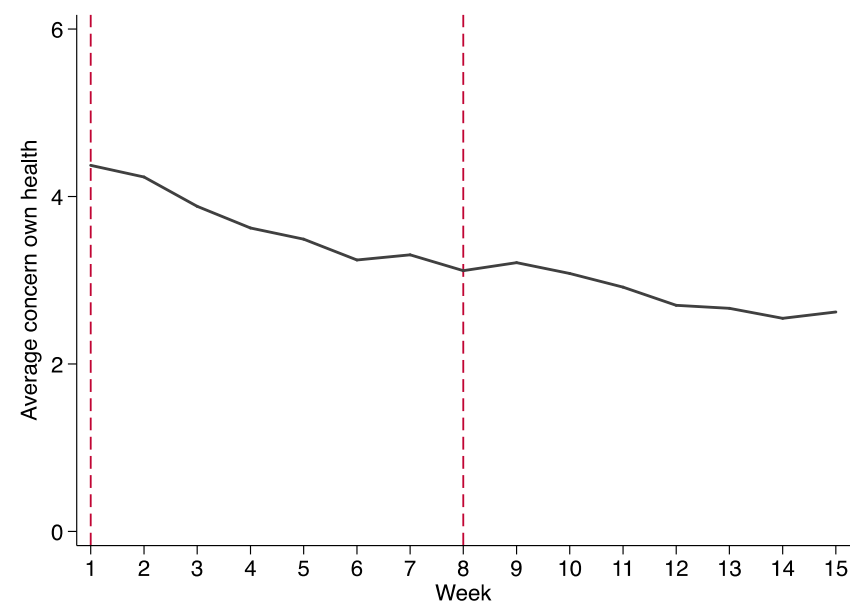

Figure S7: Evolution over time of the average current concern for own health over the period March 18-June 24, for the balanced sample.

The figure displays the evolution of the average current concern for own health over time for the balanced sample. It is equivalent to Fig. 3 for the whole sample. Participants had to indicate how concerned they were for their own health on a scale from 1 to 10 , where 1 means "not at all concerned" and 10 means "extremely concerned". The red vertical lines represent the two legal thresholds: introduction (week 1) and abrogation (week 8) of the law. 


\section{Supplementary Tables}

Table S1: Demographic characteristics

\begin{tabular}{lcc}
\hline & Full sample & Balanced sample \\
\hline $\mathbf{N}$ & $441^{\mathrm{a}}$ & 228 \\
Average age & $23.79(6.87)$ & $24.25(7.21)$ \\
Gender & & \\
Male & $37.64 \%$ & $32.02 \%$ \\
Female & $62.13 \%$ & $67.98 \%$ \\
Other & $0.23 \%$ & - \\
Number of close friends & $10.07(7.51)$ & $9.49(6.93)$ \\
Total number of friends & $313.56(372.70)$ & $311.40(368.57)$ \\
Occupation & & \\
Student & $84.35 \%$ & $81.14 \%$ \\
Employed & $11.11 \%$ & $13.60 \%$ \\
Unemployed & $3.85 \%$ & $4.38 \%$ \\
Retired & $0.68 \%$ & $0.88 \%$ \\
Education background & & \\
Management & $24.94 \%$ & $25.88 \%$ \\
Economics & $27.89 \%$ & $25.00 \%$ \\
Engineering & $20.86 \%$ & $20.61 \%$ \\
IT & $1.59 \%$ & $2.19 \%$ \\
Mathematics & $0.68 \%$ & $0.88 \%$ \\
Medicine & $5.44 \%$ & $7.02 \%$ \\
Other & $18.59 \%$ & $18.42 \%$ \\
\hline No & & \\
\hline
\end{tabular}

Notes: The table displays descriptive statistics for the full and the balanced samples. The descriptive statistics are based on self-reported data. Standard deviations in parentheses. ${ }^{\text {aThere }}$ are six missing observations on personal characteristics. 
Tables S2 and S2-a report descriptive statistics for the full and the balanced samples, respectively, based on self-reported data. The data are disaggregated by the three periods: pre-lockdown (week 0), lockdown (weeks 1-8) and post-lockdown (weeks 9-14). The question on the perceived variation in income was added in week 4.

Variable definitions

Accommodation: Last week, in what type of housing did you live?

Number of housemates: Last week, how many people lived with you?

Perceived income: As compared to last week, your income has: a) been stable; b) decreased; c) increased.

Reason for perceived lower income: a) I lost my job; b) I am in partial unemployment; c) I work less (excluding partial unemployment, including transition to part-time).

Table S2: Other characteristics (full sample)

\begin{tabular}{lccc}
\hline & $\begin{array}{c}\text { Pre-lockdown } \\
\text { (Week 0) }\end{array}$ & $\begin{array}{c}\text { Lockdown } \\
(\text { Weeks 1-8) }\end{array}$ & $\begin{array}{c}\text { Post-lockdown } \\
\text { (Weeks 9-14) }\end{array}$ \\
\hline Accommodation & & & \\
House & $16.93 \%$ & $53.47 \%$ & $42.53 \%$ \\
Flat & $66.59 \%$ & $42.22 \%$ & $51.51 \%$ \\
Student residence & $14.88 \%$ & $3.62 \%$ & $5.53 \%$ \\
Other & $1.60 \%$ & $0.69 \%$ & $0.43 \%$ \\
Number of housemates & $2.46(3.02)$ & $2.67(1.72)$ & $2.29(2.17)$ \\
Evolution of income & & & \\
Lower & & $25.61 \%$ & $12.70 \%$ \\
Stable & & $70.77 \%$ & $83.12 \%$ \\
Higher & & $3.62 \%$ & $4.18 \%$ \\
Reason for lower income & & $N=389$ & $N=316$ \\
Fired & & $28.28 \%$ & $31.02 \%$ \\
Partial unemployment & & $16.20 \%$ & $19.30 \%$ \\
Less work & & $55.52 \%$ & $49.68 \%$ \\
\hline
\end{tabular}

Notes: The table displays descriptive statistics for the full sample. The descriptive statistics are based on self-reported data. Standard deviations in parentheses. "Evolution income" relates to whether the participants reported having lower, stable or higher income at the time of the interview compared to last week. 
Table S2-a: Other characteristics (balanced sample)

\begin{tabular}{lccc}
\hline & $\begin{array}{c}\text { Pre-lockdown } \\
\text { (Week 0) }\end{array}$ & $\begin{array}{c}\text { Lockdown } \\
\text { (Weeks 1-8) }\end{array}$ & $\begin{array}{c}\text { Post-lockdown } \\
\text { (Weeks 9-14) }\end{array}$ \\
\hline Accommodation & & & \\
House & $14.60 \%$ & $51.56 \%$ & $42.41 \%$ \\
Flat & $70.80 \%$ & $45.09 \%$ & $52.53 \%$ \\
Student residence & $14.60 \%$ & $3.24 \%$ & $4.84 \%$ \\
Other & - & $0.11 \%$ & $0.22 \%$ \\
Number of housemates & $2.14(2.59)$ & $2.54(1.70)$ & $2.21(1.97)$ \\
Evolution of income & & & \\
Lower & & $26.78 \%$ & $13.76 \%$ \\
Stable & & $70.36 \%$ & $82.09 \%$ \\
Higher & & $2.86 \%$ & $4.15 \%$ \\
Reason for lower income & & $N=244$ & $N=219$ \\
Fired & & $32.79 \%$ & $35.16 \%$ \\
Partial unemployment & & $14.75 \%$ & $18.72 \%$ \\
Less work & & $52.46 \%$ & $46.12 \%$ \\
\hline
\end{tabular}

Notes: The table displays descriptive statistics for the balanced sample. The descriptive statistics are based on self-reported data. Standard deviations in parentheses. "Evolution income" relates to whether the participants reported having lower, stable or higher income at the time of the interview compared to last week. 
Tables S3 and S3-a report the average social appropriateness ratings for the full and the balanced samples, respectively. The data are disaggregated by the three periods: pre-lockdown (week 0), lockdown (weeks 1-8) and post-lockdown (weeks 9-14).

\section{Variable definition}

Average social appropriateness ratings were constructed by converting participants' responses into numerical scores using the following scale (following the procedure in Krupka and Weber 2013): "very socially inappropriate" $=-1$, "socially inappropriate" $=-2 / 3$, "somewhat socially inappropriate" $=-1 / 3$, "somewhat socially appropriate" $=1 / 3$, "socially appropriate" $=2 / 3$, "very socially appropriate" $=1$.

Table S3: Average social appropriateness (full sample)

\begin{tabular}{lccc}
\hline & $\begin{array}{c}\text { Pre-lockdown } \\
\text { Week 0 }\end{array}$ & $\begin{array}{c}\text { Lockdown } \\
\text { Weeks 1-8 }\end{array}$ & p-value \\
\hline Average appropriateness & $0.63(0.57)$ & $-0.67(0.60)$ & $<0.001$ \\
$\mathrm{~N}$ & 437 & 3041 & \\
\cline { 2 - 4 } & Lockdown & Post-lockdown & \\
\cline { 2 - 4 } Average appropriateness & Weeks 1-8 & Weeks 9-14 & \\
$\mathrm{nyyy} \mathrm{N}$ & $-0.67(0.60)$ & $0.35(0.53)$ & $<0.001$ \\
& 3041 & 2116 & \\
\cline { 2 - 4 } Average appropriateness & Pre-lockdown & Post-lockdown & \\
\cline { 2 - 4 } $\mathrm{N}$ & Week 0 & Weeks 9-14 & \\
\hline
\end{tabular}

Notes: Standard deviations are in parentheses. p-values are from Mann-Whitney tests.

Table S3-a: Average social appropriateness (balanced sample)

\begin{tabular}{lccc}
\hline & $\begin{array}{c}\text { Pre-lockdown } \\
\text { Week 0 }\end{array}$ & $\begin{array}{c}\text { Lockdown } \\
\text { Weeks 1-8 }\end{array}$ & p-value \\
\hline Average appropriateness & $0.65(0.55)$ & $-0.68(0.60)$ & $<0.001$ \\
$\mathrm{~N}$ & 226 & 1823 & \\
\cline { 2 - 4 } & Lockdown & Post-lockdown & \\
Average appropriateness & Weeks 1-8 & Weeks 9-14 & \\
\cline { 2 - 4 } $\mathrm{N}$ & $-0.68(0.60)$ & $0.36(0.53)$ & $<0.001$ \\
& 1823 & 1363 & \\
\cline { 2 - 4 } Average appropriateness & Pre-lockdown & Post-lockdown & \\
\cline { 2 - 4 } $\mathrm{N}$ & Week 0 & Weeks 9-14 & \\
\hline
\end{tabular}

Notes: Standard deviations are in parentheses. p-values are from Mann-Whitney tests. 
Tables S4 and S4-a report Ordinary Least Squares (OLS) regressions of the effect of time (dummy variables Week) on social appropriateness ratings (Model (1)) and on the frequency at which participants visited friends and family over the period March 18-June 24 (Model (2)). We controlled for participant's age, gender, education background and occupation. Table S4 refers to the full sample and Table S4-a to the balanced sample.

\section{Variable definitions}

Week 1, ..., Week 14: dummy variables for each week. Week 0 (before the law was introduced) serves as the reference group. Week 1 corresponds to the introduction of the lockdown, Week 9 is the first week after the abrogation of the law.

Social appropriateness in Model (2) captures the perception of the social norm by the participant about the social appropriateness of social gatherings.

\section{Control variables}

Age: participant's age in years.

Gender: category variable taking value 0 for male, 1 for female, 2 for other.

Education: categories are management, economics, engineering, IT, mathematics, medicine, other.

Occupation: categories are student, employed, unemployed, retired.

The regressions show that the introduction of the law in week 1 changes significantly the perception of the norm and behavior compared to the week before the lockdown (Wald tests, both $p<0.001$, full and balanced sample). Similarly, the abrogation of the law in week 8 generates a significant change in the perception of the norm and behavior in week 9 compared to the week before the abrogation (comparisons of weeks 9 and 8 , Wald tests, both $p<0.001$, full and balanced sample). The evolution is slower for the perception of the norm than for behavior, as the coefficient remains negative after abrogation but the size of the coefficients after Week 8 (Model (1), full and balanced sample) decreases significantly.

Model (2), for both the full and balanced sample, shows that the effect of time on behavior is highly non-linear: after the abrogation of the law, the Week coefficient is no longer significant and it becomes positive and significant after week 12 (week 11 for the balanced sample). It also shows that the frequency of visits to friends and family significantly increases with the perceived social norm about appropriateness of social encounters. 
Table S4: Social norm and behavior, OLS regression

\begin{tabular}{|c|c|c|}
\hline & $\begin{array}{l}\text { Social appropriateness } \\
\text { (1) }\end{array}$ & $\begin{array}{l}\text { Frequency visits } \\
\text { (2) }\end{array}$ \\
\hline Week 0 & Ref. & Ref. \\
\hline Week 1 (introduction & $-1.276^{* * *}$ & $-1.203 * * *$ \\
\hline lockdown) & $(0.043)$ & $(0.082)$ \\
\hline Week 2 & $\begin{array}{c}-1.332 * * * \\
(0.042)\end{array}$ & $\begin{array}{c}-1.156^{* * *} \\
(0.081)\end{array}$ \\
\hline Week 3 & $\begin{array}{c}-1.303 * * * \\
(0.044)\end{array}$ & $\begin{array}{c}-1.102 * * * \\
(0.084)\end{array}$ \\
\hline Week 4 & $\begin{array}{c}-1.357 * * * \\
(0.041)\end{array}$ & $\begin{array}{c}-1.053 * * * \\
(0.087)\end{array}$ \\
\hline Week 5 & $\begin{array}{c}-1.363 * * * \\
(0.041)\end{array}$ & $\begin{array}{c}-1.004 * * * \\
(0.086)\end{array}$ \\
\hline Week 6 & $\begin{array}{c}-1.334 * * * \\
(0.040)\end{array}$ & $\begin{array}{c}-0.990 * * * \\
(0.089)\end{array}$ \\
\hline Week 7 & $\begin{array}{c}-1.277 * * * \\
(0.041)\end{array}$ & $\begin{array}{c}-0.935^{* * *} \\
(0.089)\end{array}$ \\
\hline Week 8 & $\begin{array}{c}-1.160 * * * \\
(0.040)\end{array}$ & $\begin{array}{c}-0.867 * * * \\
(0.087)\end{array}$ \\
\hline Week 9 (after abrogation) & $\begin{array}{c}-0.577 * * * \\
(0.039)\end{array}$ & $\begin{array}{l}-0.086 \\
(0.087)\end{array}$ \\
\hline Week 10 & $\begin{array}{c}-0.420 * * * \\
(0.039)\end{array}$ & $\begin{array}{c}0.047 \\
(0.080)\end{array}$ \\
\hline Week 11 & $\begin{array}{c}-0.259 * * * \\
(0.036)\end{array}$ & $\begin{array}{c}0.095 \\
(0.087)\end{array}$ \\
\hline Week 12 & $\begin{array}{c}-0.207 * * * \\
(0.037)\end{array}$ & $\begin{array}{c}0.147 \\
(0.081)\end{array}$ \\
\hline Week 13 & $\begin{array}{c}-0.118 * * * \\
(0.035)\end{array}$ & $\begin{array}{c}0.259 * * \\
(0.081)\end{array}$ \\
\hline Week 14 & $\begin{array}{c}-0.122^{* * *} \\
(0.036)\end{array}$ & $\begin{array}{c}0.257 * * \\
(0.082)\end{array}$ \\
\hline Social appropriateness & . & $\begin{array}{c}0.181 * * * \\
(0.038)\end{array}$ \\
\hline Constant & $\begin{array}{c}0.753 * * * \\
(0.079)\end{array}$ & $\begin{array}{c}1.666^{* * *} \\
(0.150)\end{array}$ \\
\hline $\mathrm{N}$ & 5530 & 5530 \\
\hline Controls & Yes & Yes \\
\hline
\end{tabular}

Notes: $* \mathrm{p}<0.05,{ }^{* *} \mathrm{p}<0.01, * * * \mathrm{p}<0.001$. Standard errors, clustered at the individual level, are in parentheses. Controls are age, gender, education, occupation. In all regressions, Week 0 (before the introduction of the lockdown) serves as the reference group. 
Table S4-a: Social norm and behavior, OLS regression, balanced sample

\begin{tabular}{|c|c|c|}
\hline & $\begin{array}{l}\text { Social appropriateness } \\
\text { (1) }\end{array}$ & $\begin{array}{l}\text { Frequency visits } \\
\text { (2) }\end{array}$ \\
\hline Week 0 & Ref. & Ref. \\
\hline Week 1 (introduction & $-1.291 * * *$ & $-1.107 * * *$ \\
\hline lockdown) & $(0.059)$ & $(0.112)$ \\
\hline Week 2 & $\begin{array}{c}-1.384 * * * \\
(0.058)\end{array}$ & $\begin{array}{c}-1.078^{* * *} \\
(0.113)\end{array}$ \\
\hline Week 3 & $\begin{array}{c}-1.314 * * * \\
(0.060)\end{array}$ & $\begin{array}{c}-1.028 * * * \\
(0.113)\end{array}$ \\
\hline Week 4 & $\begin{array}{c}-1.392 * * * \\
(0.054)\end{array}$ & $\begin{array}{c}-0.913 * * * \\
(0.117)\end{array}$ \\
\hline Week 5 & $\begin{array}{c}-1.387 * * * \\
(0.054)\end{array}$ & $\begin{array}{c}-0.907 * * * \\
(0.114)\end{array}$ \\
\hline Week 6 & $\begin{array}{c}-1.370 * * * \\
(0.053)\end{array}$ & $\begin{array}{c}-0.884 * * * \\
(0.117)\end{array}$ \\
\hline Week 7 & $\begin{array}{c}-1.335 * * * \\
(0.054)\end{array}$ & $\begin{array}{c}-0.874 * * * \\
(0.118)\end{array}$ \\
\hline Week 8 & $\begin{array}{c}-1.205^{* * *} \\
(0.052)\end{array}$ & $\begin{array}{c}-0.810 * * * \\
(0.115)\end{array}$ \\
\hline Week 9 (after abrogation) & $\begin{array}{c}-0.586^{* * *} \\
(0.049)\end{array}$ & $\begin{array}{l}-0.058 \\
(0.106)\end{array}$ \\
\hline Week 10 & $\begin{array}{c}-0.455^{* * *} \\
(0.050)\end{array}$ & $\begin{array}{c}0.039 \\
(0.101)\end{array}$ \\
\hline Week 11 & $\begin{array}{c}-0.261 * * * \\
(0.047)\end{array}$ & $\begin{array}{c}0.064 \\
(0.106)\end{array}$ \\
\hline Week 12 & $\begin{array}{c}-0.220 * * * \\
(0.048)\end{array}$ & $\begin{array}{l}0.211^{*} \\
(0.098)\end{array}$ \\
\hline Week 13 & $\begin{array}{c}-0.124 * * * \\
(0.044)\end{array}$ & $\begin{array}{l}0.236^{*} \\
(0.099)\end{array}$ \\
\hline Week 14 & $\begin{array}{c}-0.135^{* * *} \\
(0.048)\end{array}$ & $\begin{array}{l}0.264^{*} \\
(0.106)\end{array}$ \\
\hline Social appropriateness & & $\begin{array}{c}0.213 * * * \\
(0.051)\end{array}$ \\
\hline Constant & $\begin{array}{c}0.696 * * * \\
(0.102)\end{array}$ & $\begin{array}{c}1.516 * * * \\
(0.188)\end{array}$ \\
\hline $\mathrm{N}$ & 3411 & 3411 \\
\hline Controls & Yes & Yes \\
\hline
\end{tabular}

Notes: $* \mathrm{p}<0.05, * * \mathrm{p}<0.01, * * * \mathrm{p}<0.001$. Standard errors, clustered at the individual level, are in parentheses. Controls are age, gender, education, occupation. In all regressions, Week 0 (before the introduction of the lockdown) serves as the reference group. 
Tables S5 and S5-a report the average frequency at which participants visited friends and family for the full and the balanced sample, respectively. The data are disaggregated by the three periods: pre-lockdown (week 0), lockdown (weeks 1-8) and post-lockdown (weeks 9-14).

\section{Variable definition}

Participants self-reported the frequency at which they visited friends and family members on a scale from 0 ("never") to 4 ("every day").

Table S5: Average frequency of family and friends visits

\begin{tabular}{lccc}
\hline & $\begin{array}{c}\text { Pre-lockdown } \\
\text { Week 0 }\end{array}$ & $\begin{array}{c}\text { Lockdown } \\
\text { Weeks 1-8 }\end{array}$ & p-value \\
\hline Average frequency & $1.60(1.26)$ & $0.32(0.76)$ & $<0.001$ \\
$\mathrm{~N}$ & 437 & 3041 & \\
\cline { 2 - 4 } & Lockdown & Post-lockdown & \\
\cline { 2 - 4 } Average frequency & Weeks 1-8 & Weeks 9-14 & $<0.001$ \\
$\mathrm{~N}$ & $0.32(0.76)$ & $1.66(1.28)$ & \\
& 3041 & 2116 & 0.3340 \\
Average frequency & Pre-lockdown & Post-lockdown & \\
$\mathrm{nyyy} \mathrm{N}$ & Week 0 & Weeks 9-14 & \\
\hline
\end{tabular}

Notes: Standard deviations are in parentheses. p-values are from Mann-Whitney tests.

Table S5-a: Average frequency of family and friends visits, balanced sample

\begin{tabular}{lccc}
\hline & $\begin{array}{c}\text { Pre-lockdown } \\
\text { Week 0 }\end{array}$ & $\begin{array}{c}\text { Lockdown } \\
\text { Weeks 1-8 }\end{array}$ & p-value \\
\hline Average frequency & $1.53(1.17)$ & $0.30(0.72)$ & $<0.001$ \\
$\mathrm{~N}$ & 226 & 1823 & \\
\cline { 2 - 4 } & Lockdown & Post-lockdown & \\
Average frequency & Weeks 1-8 & Weeks 9-14 & \\
\cline { 2 - 4 } $\mathrm{N}$ & $0.30(0.72)$ & $1.60(1.23)$ & $<0.001$ \\
& 1823 & 1363 & \\
\cline { 2 - 4 } & Pre-lockdown & Post-lockdown & \\
\cline { 2 - 4 } Average frequency & Week 0 & Weeks 9-14 & \\
$\mathrm{N}$ & $1.53(1.17)$ & $1.60(1.23)$ & \\
\hline
\end{tabular}

Notes: Standard deviations are in parentheses. p-values are from Mann-Whitney tests. 
Tables S6 and S6-a report the results of OLS regressions of social appropriateness ratings over time (dummy variables Week), controlling for prosocial types. We performed Ordinary Least Squares (OLS) regressions, and controlled for age, gender, education background and occupation. Table S6 refers to the full sample and Table S6-a to the balanced sample.

\section{Variable definitions}

All variables and controls are defined as in Table S4.

Prosocial: dummy variable taking value 1 if the participant was classified as prosocial or altruistic according to the Social Value Orientation (SVO) task, and 0 otherwise. Participants' decisions in the SVO task were translated into a score of their SVO expressed in terms of an angle, with a positive (negative) angle indicating a positive (negative) concern for the other's payoff. The SVO angle ranges from $-16.26^{\circ}$ (perfectly competitive individuals) to $61.39^{\circ}$ (perfectly altruistic individuals). Narrow self-interest would result in an angle close to $0^{\circ} .24 .6 \%$ of the decisions made by the participants showed an intransitive pattern and were therefore excluded from the analysis. $70.1 \%$ of the participants were classified as individualistic, $29.5 \%$ as prosocial, $0.3 \%$ as competitive and $0.2 \%$ as altruistic. Given the small share of competitive and altruistic types, we aggregated our data as to have only two categories: prosocial types (prosocial+altruistic) and individualistic types (individualistic+competitive).

This regression confirms the results reported in Table S4: the introduction of the law in week 1 changes significantly the perception of the norm compared to the week before the lockdown (Wald test, $p<0.001$, full and balanced sample) and its abrogation in week 8 generates a significant change in the perception of the norm in week 9 (Wald test, $p<0.001$, full and balanced sample). Moreover, it reveals that the type of the participant (prosocial $v s$. individualistic) had no significant effect on the rating of appropriateness. An alternative model has been estimated in which the participant type was interacted with the Week dummy variables. It led to the same conclusion. 
Table S6: Social norm, control for prosocial types

\begin{tabular}{|c|c|}
\hline & Social appropriateness \\
\hline Week 0 & Ref. \\
\hline Week 1 (introduction & $-1.277 * * *$ \\
\hline lockdown) & $(0.043)$ \\
\hline Week 2 & $\begin{array}{c}-1.333 * * * \\
(0.042)\end{array}$ \\
\hline Week 3 & $\begin{array}{c}-1.304 * * * \\
(0.044)\end{array}$ \\
\hline Week 4 & $\begin{array}{c}-1.357 * * * \\
(0.041)\end{array}$ \\
\hline Week 5 & $\begin{array}{c}-1.363 * * * \\
(0.041)\end{array}$ \\
\hline Week 6 & $\begin{array}{c}-1.334 * * * \\
(0.040)\end{array}$ \\
\hline Week 7 & $\begin{array}{c}-1.277 * * * \\
(0.041)\end{array}$ \\
\hline Week 8 & $\begin{array}{c}-1.160 \text { *** } \\
(0.040)\end{array}$ \\
\hline Week 9 (after abrogation) & $\begin{array}{c}-0.576 * * * \\
(0.039)\end{array}$ \\
\hline Week 10 & $\begin{array}{c}-0.420 * * * \\
(0.038)\end{array}$ \\
\hline Week 11 & $\begin{array}{c}-0.257 * * * \\
(0.036)\end{array}$ \\
\hline Week 12 & $\begin{array}{c}-0.205^{* * *} \\
(0.037)\end{array}$ \\
\hline Week 13 & $\begin{array}{c}-0.116^{* *} \\
(0.035)\end{array}$ \\
\hline Week 14 & $\begin{array}{c}-0.120 * * * \\
(0.036)\end{array}$ \\
\hline Prosocial & $\begin{array}{c}0.028 \\
(0.028)\end{array}$ \\
\hline Constant & $\begin{array}{c}0.747 * * * \\
(0.078)\end{array}$ \\
\hline $\mathrm{N}$ & 5530 \\
\hline Controls & Yes \\
\hline
\end{tabular}

Notes: $* \mathrm{p}<0.05, * * \mathrm{p}<0.01,{ }^{* * *} \mathrm{p}<0.001$. Standard errors, clustered at the individual level, are in parentheses. Controls are age, gender, education, occupation. In all regressions, Week 0 serves as the reference group. Prosocial takes value 1 if the individual is classified as a prosocial or altruistic type according to the SVO task, and 0 otherwise. 
Table S6-a: Social norm, control for prosocial types, balanced sample

\begin{tabular}{|c|c|}
\hline & Social appropriateness \\
\hline Week 0 & Ref. \\
\hline Week 1 (introduction & $-1.293 * * *$ \\
\hline lockdown) & $(0.059)$ \\
\hline Week 2 & $\begin{array}{c}-1.386 * * * \\
(0.058)\end{array}$ \\
\hline Week 3 & $\begin{array}{c}-1.316^{* * *} \\
(0.060)\end{array}$ \\
\hline Week 4 & $\begin{array}{c}-1.393 * * * \\
(0.054)\end{array}$ \\
\hline Week 5 & $\begin{array}{c}-1.389 * * * \\
(0.055)\end{array}$ \\
\hline Week 6 & $\begin{array}{c}-1.370 * * * \\
(0.053)\end{array}$ \\
\hline Week 7 & $\begin{array}{c}-1.336 * * * \\
(0.054)\end{array}$ \\
\hline Week 8 & $\begin{array}{c}-1.206 * * * \\
(0.052)\end{array}$ \\
\hline Week 9 (after abrogation) & $\begin{array}{c}-0.586 * * * \\
(0.049)\end{array}$ \\
\hline Week 10 & $\begin{array}{c}-0.456 * * * \\
(0.050)\end{array}$ \\
\hline Week 11 & $\begin{array}{c}-0.260 * * * \\
(0.047)\end{array}$ \\
\hline Week 12 & $\begin{array}{c}-0.219 * * * \\
(0.048)\end{array}$ \\
\hline Week 13 & $\begin{array}{c}-0.124 * * \\
(0.044)\end{array}$ \\
\hline Week 14 & $\begin{array}{c}-0.135^{* *} \\
(0.048)\end{array}$ \\
\hline Prosocial & $\begin{array}{c}0.039 \\
(0.037)\end{array}$ \\
\hline Constant & $\begin{array}{c}0.688 * * * \\
(0.101)\end{array}$ \\
\hline $\mathrm{N}$ & 3411 \\
\hline Controls & Yes \\
\hline
\end{tabular}

Notes: $* \mathrm{p}<0.05, * * \mathrm{p}<0.01,{ }^{* * *} \mathrm{p}<0.001$. Standard errors, clustered at the individual level, are in parentheses. Controls are age, gender, education, occupation. In all regressions, Week 0 serves as the reference group. Prosocial takes value 1 if the individual is classified as a prosocial or altruistic type according to the SVO task, and 0 otherwise. 